Afiasi: Jurnal Kesehatan Masyarakat, Vol. 4, No. 3, Desember 2019:105-1111SSN Print : 2442-5885

Journal homepage: http://afiasi.unwir.ac.id

ISSN Online : 2622-3392

\title{
HUBUNGAN DUKUNGAN KELUARGA TERHADAP DEPRESI DAN INTERAKSI SOSIAL PADA LANSIA
}

\section{The correlation og Family Support for Depression and Social Interaction in Elderly}

\author{
Rini Andriyani ${ }^{1}$, Yecy Anggreny ${ }^{2}$, Agnita Utami $^{3}$ \\ Program Studi: S1 Ilmu Keperawatan STIKes Hang Tuah Pekanbaru \\ Email : riniandriyani@gmail.com
}

\begin{abstract}
ABSTRAK
Dukungan keluarga merupakan unsur terpenting dalam membantu lansia dalam menyelesaikan masalah. Dukungan keluarga yang tidak baik bisa menyebabkan depresi pada lansia, yang akan berdampak pada interaksi sosial lansia menjadi buruk, lansia lebih suka mengurung diri dirumah dan tidak mau bersosialisasi dimasyarakat. Penelitian ini bertujuan untuk mengetahui hubungan dukungan keluarga terhadap depresi dan interaksi sosial pada lansia di Wilayah Kerja Puskesmas Payung Sekaki Pekanbaru. Jenis penelitian ini kuantitatif dengan pendekatan cross sectional menggunakan teknik Accidental Sampling sebanyak 36 responden. Hasil bivariat didapatkan adanya hubungan dukungan keluarga terhadap depresi ( $P$-value: 0,015$)$ dan terdapat hubungan dukungan keluarga terhadap interaksi sosial lansia ( $P$-value: 0,009). Untuk itu disarankan kepada keluarga untuk memberikan dukungan keluarga kepada lansia agar terhindar dari depresi dan interaksi sosial yang buruk.

Kata Kunci: Depresi, Dukungan Keluarga, Interaksi Sosial
\end{abstract}

\begin{abstract}
Family support is the most important element in helping elderly people solve problems. Poor family support can cause depression in the elderly, which will have an impact on elderly social interaction to be worse, elderly prefer to confine themselves at home and do not want to socialize in the community. This study aims to determine the relationship of family support for depression and social interaction in the elderly in the Working Area of the Payung Sekaki Health Center Pekanbaru. This type of research was quantitative with a cross sectional approach using Accidental Sampling techniques with 36 respondents. Bivariate results showed that there was a relationship of family support for depression (P-value: 0.015) and there was a relationship of family support for elderly social interaction (P-value: 0.009). It was suggested to families to provide family support to the elderly to avoid depression and bad socialinteraction.
\end{abstract}

Key words: Depression, Family Support, Social Interaction

\section{PENDAHULUAN}

Lanjut usia (lansia) merupakan kelompok umur pada manusia yang memasuki tahapan akhir dari fase kehidupan. Perkembangan fisik pada masa lansia terlihat adanya perubahan fisiologis yang bisa dikatakan mengalami kemunduran dan perubahan-perubahan biologis yang dialami pada masa lansia ${ }^{1}$. Lansia adalah seseorang yang karena usianya mengalami perubahan biologis, fisik, kejiwaan, dan sosial. Perubahan ini akan memberikan pengaruh pada seluruh aspek kehidupan, termasuk kesehatan ${ }^{2}$.

Dukungan dari keluarga merupakan unsur terpenting dalam membantu individu menyelesaikan masalah. Adanya dukungan rasa percaya diri akan menjadi bertambah dan bermotivasi untuk menghadapi masalah yang terjadi akan meningkat.

Dukungan keluarga tidak baik bisa menyebabkan stres pada lansia, stres merupakan suatu kondisi situasi internal atau lingkungan yang membebankan tuntutan penyesuaian terhadap individu yang bersangkutan, stres yang dialami oleh lansia akan lama kelamaan menyebabkan depresi ${ }^{3}$.

Pravelansi depresi pada lansia diseluruh dunia pada tahun 2014 berkisar 13,5\% dari seluruh jumlah lansia dengan perbandingan wanita sebanyak $8,4 \%$ dan pria sebanyak $5,1 \%$. Sedangkan di indonesia prevalansi lansia sebanyak 20.893.000 jiwa dengan jumlah lansia yang mengalami depresi ringan sampai berat sebanyak $32 \%$. Sedangkan menurut kemenkes 2013 prevalansi depresi lansia berusia 55-64 tahun yang mengalami depresi sebesar $15,9 \%$, lansia usia 65-74 tahun sebesar $23,2 \%$ dan lansia usia diatas 75 tahun sebesar $33,7 \%{ }^{4}$. Depresi merupakan gangguan mental yang sering terjadi di tengah masyarakat, berawal dari stres yang tidak diatasi maka seseorang bisa jatuh ke fase depresi ${ }^{1}$. 
Lansia yang mengalami depresi akan menyebabkan interaksi sosial yang buruk, bentuk interaksi sosial yang buruk pada lansia saat ini adalah lansia lebih sukamengurung diri dirumah dan tidak mau bersosialisasi dimasyarakat. Interaksi sosial sangat penting dalam kehidupan lansia. Kesepian dan terisolasi secara sosial akan berpengaruh terhadap hubungan sosial, baik sesama lansia maupun dengan pengasuh ${ }^{5}$.

Semakin besar interaksi sosial maka semakin besar perasaan tidak kesepian. Hasil penelitian menunjukkan responden mengalami interaksi sosial baik sebesar $48,8 \%$ dan sebanyak 34 responden $82,9 \%$ merasa tidak kesepian ${ }^{6}$.

Survei awal yang telah dilakukan oleh peneliti di wilayah kerja Puskesmas Payung Sekaki terhadap 10 orang lansia yang telah dilakukan wawancara 4 lansia diantaranya tidak mengalami depresi, sedangkan 6 lansia lain mengalami depresi. Hal ini dikaji dengan melakukan wawancara mendalam menggunakan alat ukur GDS (Geriatric Depression Scale) dengan menilai poinpoin yang telah ditetapkan pada alat ukur GDS sesuai dengan jawaban dari pertanyaan yang telah diberikan.Tujuan penelitian ini adalah untuk mengetahui hubungan dukungan keluarga terhadap depresi dan interaksi sosial pada lansia di Wilayah Kerja Puskesmas Payung Sekaki.

\section{METODOLOGI}

Penelitian ini kuantitatif dengan desain Cross sectional. Penelitian dilakukan di Wilayajh Kerja Puskesmas Payung Sekaki Kota Pekanbaru mulai Desember 2017 sampai dengan Agustus 2018. Populasi dalam penelitian ini yaitu lansia di Wilayah Kerja Puskesmas Payung Sekaki Kota Pekanbaru sebanyak 106.021 Lansia dengan sampel 36 orang lansia. Didalam peneliti ini menggunakan teknik accidental sampling, dilakukan dengan mengambil kasus / responden yang kebetulan ada tersedia disuatu tempat sesuai dengan konteks.

\section{HASIL}

Analisa Univariat

1. Karakteristik Responden a. Berdasarkan Jenis Kelamin

Tabel 1 Distribusi Frekuensi Berdasarkan Jenis Kelamin Lansia Di Wilayah Kerja Puskesmas Payung Sekaki Kota Pekanbaru

\begin{tabular}{cccc}
\hline No & $\begin{array}{c}\text { Jenis } \\
\text { Kelamin }\end{array}$ & $\begin{array}{c}\text { Frekuensi } \\
(\mathbf{n})\end{array}$ & $\begin{array}{c}\text { Persentase } \\
(\boldsymbol{\%})\end{array}$ \\
\hline 1. & Laki- laki & 13 & 36,1 \\
\hline 2. & Perempuan & 23 & 63,9 \\
\hline & Total & 36 & 100,0 \\
\hline
\end{tabular}

Berdasarkan Tabel 1 distribusi frekuen si berdasarkan jenis kelamin responden lansia di Wilayah Kerja Puskesmas Payung Sekaki Kota Pekanbaru diatas menunjukkan bahwa sebagian besar responden berjenis kelamin perempuan sebanyak 23 responden $(63,9 \%)$

\section{b. Berdasarkan Umur}

Tabel 2. Distribusi Frekuesi Berdasarkan Umur Lansia Di Wilayah Kerja Puskesmas Payung Sekaki Kota Pekanbaru

\begin{tabular}{ccccc}
\hline Mean & Median & $\begin{array}{c}\text { Std. } \\
\text { Deviasi }\end{array}$ & Min & Max \\
\hline 66,72 & 65,50 & 4,902 & 60 & 72 \\
Tahun & Tahun & & Tahun & Tahun \\
\hline
\end{tabular}

Berdasarkan Tabel 2 didapatkan bahwa, rata-rata umur lansia di Wilayah Kerja Puskesmas Payung Sekaki adalah 66,72 tahun dengan umur minimum 60 tahun dan umur maximum 72 tahun. 
Afiasi: Jurnal Kesehatan Masyarakat, Vol. 4, No. 3, Desember 2019:105-111ISSN Print : 2442-5885 Journal homepage: http://afiasi.unwir.ac.id

ISSN Online : 2622-3392

c. Dukungan Keluarga

Tabel 3 Distribusi Frekuensi Berdasarkan Dukungan Keluarga di Wilayah Kerja Puskesmas di Kota Pekanbaru

\begin{tabular}{cccc}
\hline No & $\begin{array}{c}\text { Dukungan } \\
\text { Keluarga }\end{array}$ & $\begin{array}{c}\text { Frekuensi } \\
(\mathbf{n})\end{array}$ & $\begin{array}{c}\text { Persentase } \\
(\mathbf{\%})\end{array}$ \\
\hline 1. & Baik & 12 & 33,3 \\
\hline 2. & Kurang & 24 & 66,7 \\
\hline & Total & $\mathbf{3 6}$ & $\mathbf{1 0 0 , 0}$ \\
\hline
\end{tabular}

Berdasarkan tabel 3 distribusi frekuensi berdasarkan dukungan keluarga lansia di Wilayah Kerja Puskesmas Payung Sekaki Kota Pekanbaru dapat dilihat sebagian besar responden memiliki dukungan keluarga yang kurang yaitu sebanyak 24 responden $(66,7 \%)$.

\section{d. Depresi}

Tabel 4 Distribusi $\quad$ Frekuensi Berdasarkan Depresi Lansia di Wilayah Kerja Puskesmas Payung Sekaki di Kota Pekanbaru

\begin{tabular}{cccc}
\hline No & Depresi & $\begin{array}{c}\text { Frekuensi } \\
(\mathbf{n})\end{array}$ & $\begin{array}{c}\text { Persentase } \\
(\mathbf{\%})\end{array}$ \\
\hline 1. & Depresi & 14 & $58,3 \%$ \\
\hline 2. & $\begin{array}{c}\text { Tidak } \\
\text { Depresi }\end{array}$ & 10 & $41,7 \%$ \\
\hline & Total & $\mathbf{2 4}$ & $\mathbf{1 0 0 , 0 \%}$
\end{tabular}

Berdasarkan tabel 4 distrbusi frekuensi berdasarkan depresi lansia di Wilayah Kerja Puskesmas Payung Sekaki di Kota pekanbaru dapat dilihat lansia depresi 14 $(58,3 \%)$ dan tidak depresi $10(41,7 \%)$.

\section{e. Interaksi Sosial Lansia}

Tabel 5 Distribusi Frekuensi Berdasarkan Interaksi Sosial Lansia Di Wilayah Kerja Puskesmas Payung Sekaki Kota Pekanbaru

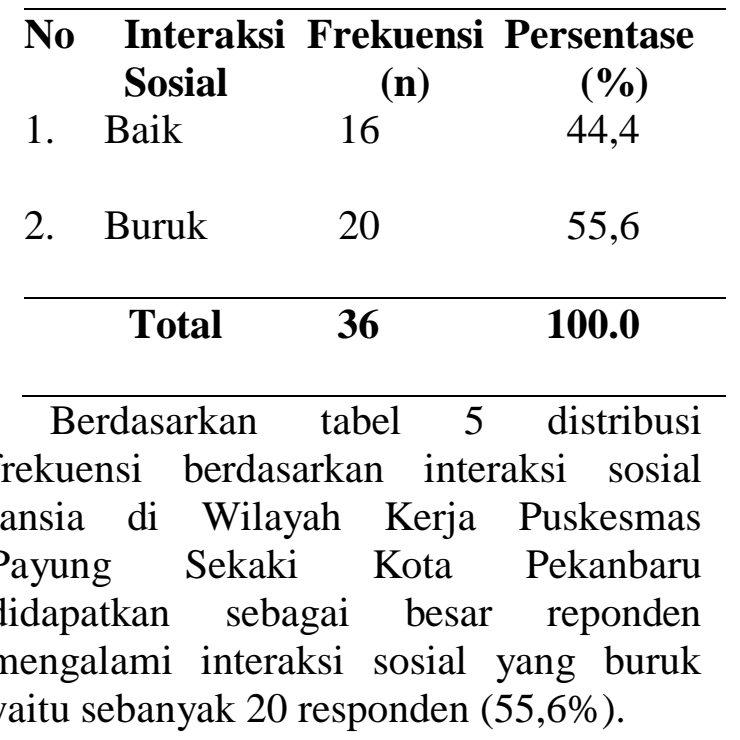

Hasil Penelitian
Analisa Bivariat

Tabel 6

Hubungan Dukungan Keluarga terhadap Depresi dan Lansia di Wilayah Kerja Puskesmas Payung Sekaki di Kota Pekanbaru

\begin{tabular}{cccccccc}
\hline \multirow{2}{*}{$\begin{array}{c}\text { Dukungan } \\
\text { Keluarga }\end{array}$} & \multicolumn{2}{c}{ Tidak Depresi } & \multicolumn{2}{c}{ Depresi } & \multicolumn{2}{c}{ Total } & P Value \\
\cline { 2 - 7 } & $\mathrm{n}$ & $\mathbf{\%}$ & $\mathrm{N}$ & $\mathbf{\%}$ & $\mathbf{n}$ & $\mathbf{\%}$ & \\
\hline Kurang & 14 & 58,3 & 10 & 41,7 & 24 & 66,7 & \\
\hline Baik & 12 & 100,0 & 0 & 0 & 12 & 33,3 & $\mathbf{0 , 0 1 5}$ \\
\hline Total & $\mathbf{2 6}$ & $\mathbf{7 2 , 2}$ & $\mathbf{1 0}$ & $\mathbf{2 7 , 8}$ & $\mathbf{3 6}$ & $\mathbf{1 0 0 , 0}$ & \\
\hline
\end{tabular}


Afiasi: Jurnal Kesehatan Masyarakat, Vol. 4, No. 3, Desember 2019:105-1111SSN Print : 2442-5885 Journal homepage: http://afiasi.unwir.ac.id

ISSN Online : 2622-3392

Berdasarkan tabel 6 diatas dapat disimpulkan bahwa dari 36 responden lansia yang memiliki dukungan keluarga kurang sebanyak 24 responden $(66,7 \%)$, dukungan keluarga kurang yang mengalami tidak depresi sebanyak 14 responden (58,3\%), dan yang mengalami depresi 10 responden $(41,7 \%)$. Sedangkan dukungan keluarga baik sebanyak 12 responden
$(33,3 \%)$, yang mengalami tidak depresi sebanyak 12 responden $(100,0 \%)$, dan dukungan keluarga baik yang mengalami depresi sebanyak 0 responden $(0 \%)$. Hasil uji statistik menggunakan uji Fisher's Exact Test diperoleh $p$ value $=0,15>0,05$ yang artinya terdapat hubungan antara dukungan keluarga dengan depresi pada lansia, sehingga Ha diterima.

Tabel 7. Hubungan dukungan keluarga dengan interaksi sosial lansia di Wilayah Kerja Puskesmas Payung Sekaki Kota Pekanbaru

\begin{tabular}{|c|c|c|c|c|c|c|c|}
\hline \multirow{3}{*}{$\begin{array}{c}\text { Dukungan } \\
\text { Keluarga }\end{array}$} & \multicolumn{6}{|c|}{ Interaksi Sosial Lansia } & \multirow{3}{*}{ P Value } \\
\hline & \multicolumn{2}{|c|}{ Baik } & \multicolumn{2}{|c|}{ Buruk } & \multicolumn{2}{|c|}{ Total } & \\
\hline & $\mathbf{N}$ & $\%$ & $\mathbf{N}$ & $\%$ & $\mathbf{N}$ & $\%$ & \\
\hline Baik & 9 & 5,3 & 3 & 6,7 & 12 & 12,0 & \multirow{2}{*}{0,009} \\
\hline Kurang & 7 & 10,7 & 17 & 13,3 & 24 & 24,0 & \\
\hline Total & 16 & 16,0 & 20 & 20,0 & 36 & 36,0 & \\
\hline
\end{tabular}

Berdasarkan tabel 7 di atas dapat disimpulkan bahwa dari 36 responden dukungan keluarga baik sebanyak 12 responden $(12,0 \%)$ yang mengalami interaksi sosial baik sebanyak 9 responden $(5,3 \%)$ dan interaksi sosial buruk sebanyak 3 responden $(6,7 \%)$. Sedangkan, dukungan keluarga kurang sebanyak 24 responden $(24,0 \%)$ yang memiliki interaksi sosial baik sebanyak 7 responden $(10,7 \%)$ dan interaksi sosialnya buruk sebanyak 17 responden $(13,3 \%)$. Hasil uji statistik menggunakan uji chi square diperoleh $p$ value $=0,009>0,05$ yang artinya terdapat hubungan antara dukungan keluarga dengan interaksi sosial pada lansia, sehingga Ha diterima.

\section{PEMBAHASAN}

\section{Karakteristik Responden}

\section{Jenis Kelamin}

Berdasarkan kuesioner yang dikumpulkan dari 36 orang responden diperoleh data tentang karakteristik responden berdasarkan jenis kelamin dan umur. Pada penelitian ini didapatkan bahwa responden berjenis kelamin perempuan sebanyak 23 responden $(63,9 \%)$ dan laki - laki sebanyak 13 responden $(13,1 \%)$. Angka harapan hidup antara perempuan dan lakilaki memiliki perbedaan, dimana angka harapan hidup pada perempuan lebih tinggi dibandingkan dengan laki-laki. Perbedaan angka harapan hidup ini dapat diakibatkan oleh beberapa

faktor, diantaranya gaya hidup, perilaku, serta lingkungannya ${ }^{7}$.

Beberapa macam faktor dimana salah satunya ada faktor biologis dan lingkungan. Faktor faktor tersebut akan menimbulkan berbagai macam stessor pada perempuan, misalnya dari segi penghasilan dan juga pendidikan yang lebih rendah dibandingkan dengan laki - laki. Selain itu juga terdapat faktor kesehatan, misalnya yang melibatkan sistem reproduksi dan hormon yang terdapat pada perempuan. Lansia yang berjenis kelamin perempuan cenderung memiliki umur yang panjang. Hal ini dikarenakan faktor seperti gaya hidup, dibandingkan dengan lansia berjenis kelamin laki-laki ${ }^{6}$. Hasil penelitian Idris menunjukkan bahwa, faktor support system keluarga merupakan faktor yang dapat menentukan tingkat stress psikososial lansia dimana semakin tinggi support system keluarga maka semakin kecil tingkat stres psikososial yang dialami lansia ${ }^{8}$. 


\section{Umur}

Berdasarkan kuesioner yang dikumpulkan 36 orang responden diperoleh data tentang karakteristik responden berdasarkan umur. Pada penelitian ini bahwa sebagian besar responden umur lansia berada pada umur 65 tahun sebanyak 10 responden $(27,8 \%)$.

Banyak orang berasumsi jika seseorang sudah tua maka fisik akan semakin melemah, banyak penyakit, cepat lupa, penampilan semakin tidak menarik dan semakin banyak hambatan lain yang membuat hidup semakin terbatas? Seseorang yang telah pensiun mengangap dirinya tidak berguna dan tidak dibutuhkan lagi karena usia tua dan produktifitasnya menurun, sehingga tidak menguntungkan lagi bagi tempat mereka bekerja. Sering kali masalah lansia menjadi over sensitif dan subjektif terhadap stimulus yang ditangkap, sehingga hal tersebut menyebabkan lansia jadi sakit-sakitan saat pensiun tiba. Jika masalah tersebut tidak diatasi dengan baik maka akan menyebabkan depresi pada lansia dan berpengaruh terhadap interaksi sosial lansia.

\section{Varibel Penelitian}

\section{Hubungan Dukungan Keluarga terhadap Depresi}

Berdasarkan hasil penelitian yang dilakukan terhadap 36 responden di Wilayah Kerja Puskesmas Payung Sekaki Kota Pekanbaru didapatkan responden memiliki dukungan keluarga yang baik sebanyak 12 responden, yang mengalami tidak depresi sebanyak 12 responden, dan memiliki tingkat depresi sebanyak 0 responden. Hasil penelitian ini dilakukan uji statistik menggunakan uji Fisher's Exact Test dengan $p$ value $=0,015$ yang berarti $p$ value $<0,05$ sehingga secara statistik hal tersebut menunjukkan ada hubungan dukungan keluarga terhadap depresi pada lansia.

Hasil penelitian ini sejalan dengan penelitian lainnya yang dilakukan pada Lansia yang Tinggal Bersama Keluarga Lampung Utara. Didapatkan hasil penelitian adanya hubungan yang signifikan antara dukungan keluarga dengan kejadian depresi pada lansia. Hal ini dikarenakan upaya dalam mencegah dan mengatasi lansia dari depresi berat dapat dilakukan perawatan dan pengobatan, upaya tersebut dapat dibentuk dengan memberikan terapi psikologi seperti latihan kognitif yang dilaksanakan secara rutin padaposyandu lansia secara jadwal ${ }^{9}$.

Depresi pada lansia sering terjadi dengan masalah dengan gangguan fisik yang dialami. Gangguan penglihatan ataupun pendengaran yang umum terjadi pada lansia juga dapat mengalami depresi. Sehingga, dukungan keluarga sangat penting dan sangat dibutuhkan pada lansia, mereka perlu didorong agar terlibat dalam kegiatan yng berguna dan berarti akan menghasilkan pengalaman untuk lansia ${ }^{10}$.

Dukungan keluarga yang baik dikarenakan keluarga selalu mendukung dan mengisi kekosongan lansia sehingga lansia merasa tidak kesepian ${ }^{11 .}$ Tingkat depresi yang dialami lansia normal atau tidak depresi karena lansia memiliki aktivitas fisik yang membuat lansia untuk berfikir positif tentang kehidupannya ${ }^{12}$.

Faktor pencetus meningkatnya kejadian depresi (dari ringan menjadi berat), lansia akan mengalami rasa cemas yang tinggi, sering menangis dan akhirnya akan merasa lemah serta kurang semnagat hidup. Bla depresi sudah timbul maka akan sangat menguras emosi, finansial baik bagipenderita maupun bagi keluarga, hampir semua populasi lanjut usia lebih membutuhkan dukungan emosinal ${ }^{13}$.

Hasil penelitian ini juga sejalan dengan penelitian lainnya diamana terdapat hubungan dukungan keluarga dengan pencegahan depresi ${ }^{14}$. Cara mencegah kejadian depresi yang dialami lansia, maka dukungan keluarga yang diperlukan seperti memberi kesempatan kepada lansia untuk berperan serta dalam kegiatan pencegahan terhadap gangguan kesehatan, seperti tidak melarang melakukan olah raga yang tidak berat, memberikan kenyamanan dalam hal meningkatkan penyembuhan lanisa secara 
mandiri, seperti memberikan kesempatan kepada lansia untuk berinteraksi dimasyarakat dengan masyarakat dan memberikan pengobatan untuk mengatasi penyakit dan gejala-gejala yang penting untuk penyembuhan dan peningkatan kemandirian lansia.

Penelit menyimpulkan bahwa dukungan keluarga yang dilakukan kelurga dalam pencegahan depresi keluarga dalam pencegahan depresi pada lansia dengan memberikan dukungan informasional berupa nasehat, usulan,saran, petunjuk dan pemberi informasi yang diberikan keluarga, sedangkan dukungan penghargaan berupa keluarga memberikan suport, penghargaan dan perhatian kepada saat lansia dalam melakukan aktivitas kesehariannya, untuk dukungan instrumental berupa memberi kecukupan kebutuhan lansia seperti makanan yang sehat sehingga mampu mempertahankan kesehatan lansia serta dukungan emosional bentuk afektif, adanya kepercayan, perhatian dan mendengarkan keluhan yang dialami lansia.

\section{Hubungan Dukungan Keluarga terhadap Interaksi Sosial}

Berdasarkan hasil penelitian yang dilakukan terdapat 36 lansia di Wilayah Kerja Puskemas Payung Sekaki Kota Pekanbaru didapatkan mayoritas responden memiliki dukungan keluarga yang kurang dengan interaksi sosial yang baik sebanyak 7 responden sedangkan interaksi sosial yang buruk pada lansia sebanyak 17 responden. Hasil penelitian ini dilakukan uji statistik menggunakan uji chi square dengan $\alpha=0,05$ didapatkan $p$ value $0,009<0,05$ sehingga secara statistik hal tersebut menunjukkan terdapatnya hubungan yang signifikan antara dukungan keluarga dan interaksi sosial lansia.

Adanya hubungan dukungan keluarga dengan kepuasaan interaksi sosial pada lansia dikarenakan adanya faktor saling keterikatan antara anggota keluarga yang lain. Keluarga yang mendukung lansia dalam melakukan aktifitas dan membicarakan setiap masalah yang ada, maka akan memberi dampak yang positif seperti memberi rasa kehangatan dan suasana damai dalam lingkungan keluarga $^{14}$.

Dukungan keluarg dalam interaksi sosial sangat penting untuk mengurangi mencegah dan timbulnya penurunan fungsi ${ }^{15}$.Dukungan interaksi sosial ini dapat dilakukan keluarga melalui sikap dan perilaku keluarga seperti tetap menghargai lansia sebagai bagian dari keluarga, mendorong lansia untuk berbagai perhatian, dan dapat melakukan aktivitas secara bersama-sama yang kreatif dan inovatif. Lansia dapat berkumpul bersama orang seusianya sehingga mereka dapat saling mengikuti kegiatan yang mendukung terhadap perkembangan lansia seperti kegiatan pengajian, posyandu lansia dan kegiatan sosial yang ada di lingkungan. Dengan interaksi sosial yang bagus memungkinkan lansia untuk mendapatkan perasaan memiliki suatu kelompok sehingga dapat berbagai cerita berbagai minat, berbagai perhatian dan dapat melakukan aktivitas secara bersama-sama yang kreatif dan inovatif. Lansia dapat berkumpul bersama orang seusianya sehingga mereka dapat saling menyemangati dan berbagai mengenai masalahnya.

Interaksi sosial dan dukungan keluarga merupakan faktor penting bagi lansia untuk menuju masa tua yang sukses dan bahagia. Banyak lansia terutama yang pasangan telah meninggal atau hidup sendiri dalam sepi mengalami ketakutan dan akhirnya menderita depresi ${ }^{16}$.

Peneliti beranggapan mayoritas responden dalam penelitian ini yang memiliki dukungan keluarga kurang baik menyebabkan interaksi sosial yang buruk, hal ini karena interaksi sosial yang kurang cenderung memiliki kualitas hidup yang kurang, hal ini dapat disebabkan karena dengan adanya kurang interaksi sosial secara tidak langsung akan berpengaruh terhadap pengetahuan atau informasi yang didapatnya, dan juga menyebabkan kekurangan perhatian dari orag lain yang selanjutnya akan berdampak pada kualitas 
Afiasi: Jurnal Kesehatan Masyarakat, Vol. 4, No. 3, Desember 2019:105-1111SSN Print : 2442-5885 Journal homepage: http://afiasi.unwir.ac.id

ISSN Online : 2622-3392

hidup lansia tersebut.

\section{KESIMPULAN}

Berdasarkan penelitian yang telah dilakukan oleh peneliti di Puskesmas Payung Sekaki mengenai hubungan dukungan keluarga terhadap depresi dan interaksi sosial pada lansia. Didapatkan hasil dari 36 responden dengan rata-rata umur 66 dengan mayoritas jenis kelamin perempun. Untuk gambaran univariat didapatkan hasil yang terbanyak di dukungan keluarga terdapat dukungan keluarga kurang, didapatkan lansia yang depresi dan mengalami interaksi sosial yang buruk. Hasil yang didapatkan dari bivariat terdapat ada hubungna antara dukungan keluarga dengan depresi dan hubungan dukungan keluarga terhadap interaksi sosial pada lansia, karena dukungan keluarga merupakan hal penting bagi lansia terutama dalam mencegah terjadinya depresi pada lansia dan interaksi sosial, karena dukungan keluarga yangbaik akan menyebabkan lansia merasa bersemangat dan menjalan kan komunikas dan berinteraksi sosial dengan baik.

\section{SARAN}

\section{Bagi Keluarga}

Hasil penelitian ini dapat menambah wawasan dan menambah kesadaraan keluarga tentang perlunya memberi dukungan kepada lansia agar terhindar daridepresi dan interaksi sosial yang buruk pada lansia.

2. Bagi Ilmu keperawatan

Hasil penelitian ini dapat menjadi sumber masukkan bagi perkembangan ilmu keperawatan untuk lebih dapat aktifmemberikan penyuluhan tentang perlunya dukungan keluarga pada lansia agar tidak terjadi interaksi sosial yang buruk dan depresi padalansia.

3. Bagi peneliti selanjutnya

Hasil penelitian ini dapat menjadi pedoman atau referensi tambahan bagipeneliti selanjutnya yang ingin meneliti lebih dalam tentang depresi lansia, seperti meneliti tentang faktor- faktor yang mempengaruhi terjadinya depresi pada lansia.

4. Bagi Puskesmas

Hasil penelitian ini dapat menjadi sumber masukkan bagi puskesmas agar dapat meningkatkan mutu pelayanan petugas kesehatan seperti aktif dalam memberikan penyuluhan kepada masyarakat di Wilayah Kerja Puskesmas Payung Sekaki khususnya tentang pentingnya dukungan keluarga pada lansia untuk mencegah terjadinya depresi dan interaksi sosial yang buruk pada lansia.

\section{DAFTAR PUSTAKA}

1. Lubis, N. L. 2009. Depresi Tinjauan psikologis. Jakarta: Kencana Prenada Media Group

2. Fatimah. 2010. Merawat manusia lanjut usia suatu pendekatan proses keperawatan gerontik. Jakarta: CV Trans Info Media.

3. Tamher, N. K. 2009 Kesehatan usia lanjut dengan pendekatan asuhan keperawatan. Jakarta: Salemba Medika.

4. Kemengkes, RI. 2013. Riset Kesehatan Dasar (Riskesdas) Tahun 2013: Gangguan Mental Emosional

5. Santrock. 2007. Buku ajar keperawatan gerontik. Jakarta: EGC

6. Tamher, N. K. 2009 Kesehatan usia lanjut dengan pendekatan asuhan keperawatan. Jakarta: Salemba Medika.

7. Kemengkes, RI. 2013. Riset Kesehatan Dasar (Riskesdas) Tahun 2013: Gangguan Mental Emosional

8. Santrock. 2007. Buku ajar keperawatan gerontik. Jakarta: EGC

9. Sanjaya, A. 2012. Hubungan interaksi sosial dengan kesepian pada lansia. Jurnal Keperawatan Holistik, 1(2).

10. Rahaja, E. 2013. Hubungan antara tingkat depresi dengan kejadian insomnia pada lanjut usia di Karang Werdha Semuru Jaya Kecamatan Sumbersari Kabupaten Jember. Universitas Jember:55-61.

11. Idris, R 2006. Faktor- faktor yang berhubungan dengan stres psikososial 
lansia di panti sosial tresna werdha gau Kabupaten Gowa Sulawesi Selatan: Universitas Hasanuddin Makasar. Jurnal lantera, 5(1).

12. Fepi, S., \& Yenie, H. 2015. Hubungan dukungan keluarga terhadap depresi pada lansia yang tinggal bersama keluarga di wilayah kerja puskesmas kota bumi II lampung utara. Jurnal Kesehatan Metro Saiwawai, 8(2).

13. Santoso, H., \& Ismail, A. 2009. Memahami krisis lanjut usia. Jakarta: Mulia

14. Darmojo. 2004. Buku ajar geriatri ilmu kesehatan lanjut usia. Jakarta: Balaipenerbit FKUI.

15. Stanley, M., \& Beare, G. P. 2007. Buku ajar keperawatan gerontik edisi 2. Jakarta:EGC

16. Nurhidayati,F.H.D.K., dan Wahidyanti, R. H. 2017. Hubungan dukungan keluarga dengan pencegahan depresi pada lansia. Jurnal Medika, 2(2). 